\title{
REALIDADE VIRTUAL, PSICOMOTRICIDADE E MUSICOTERAPIA COMO FORMAS DE TRATAMENTO DA CRIANÇA AUTISTA: UMA REVISÃO BIBLIOGRÁFICA
}

\section{ARTIGO DE REVISÃO}

MAGALHÃES, Luiza Lopes ${ }^{1}$

LIMA, Valdineide Alves ${ }^{2}$

DOTA, Lilian ${ }^{3}$

DOTA, Liliane ${ }^{4}$

SALLES, Adriana Oliveira ${ }^{5}$

MENDES, Zarif Torres Rehder ${ }^{6}$

MAGALHÃES, Luiza Lopes. Et al. Realidade virtual, psicomotricidade e musicoterapia como formas de tratamento da criança autista: Uma revisão bibliográfica. Revista Científica Multidisciplinar Núcleo do Conhecimento. Ano 05, Ed. 08, Vol. 15, pp. 130-140. Agosto de 2020. ISSN: 2448-0959, Link de acesso: https://www.nucleodoconhecimento.com.br/saude/psicomotricidade-emusicoterapia

\footnotetext{
${ }^{1}$ Graduanda em Fisioterapia.

2 Técnico em Enfermagem; Instrumentação Cirúrgica; Graduanda em Fisioterapia.

${ }^{3}$ Técnico em Administração; Graduanda em Fisioterapia.

${ }^{4}$ Técnico em Administração; Graduanda em Fisioterapia.

${ }^{5}$ Graduanda em Fisioterapia.

${ }^{6}$ Mestrado em Biologia Celular e Estrutural (UNICAMP); Graduação em Fisioterapia (PUCCAMP).
} 


\section{RESUMO}

O transtorno do espectro do autismo é caracterizado como uma síndrome comportamental, que apresenta algumas características como a dificuldade na interação social, na linguagem e distúrbios comportamentais. Por meio de uma revisão bibliográfica, o presente estudo teve como objetivo apresentar algumas formas de intervenções terapêuticas em crianças autistas, como a psicomotricidade, o uso da realidade virtual e a musicoterapia. Por meio da estimulação precoce, foram relatados que as intervenções contribuem para o desenvolvimento cognitivo, sensorial, motor, social e linguístico das crianças, favorecendo a plasticidade cerebral.

Palavras chaves: Autismo, intervenções, musicoterapia, psicomotricidade, realidade virtual.

\section{INTRODUÇÃO}

O Transtorno do Espectro do Autismo (TEA) é caracterizado como uma síndrome comportamental, apresentando algumas características como dificuldade na interação social, na linguagem e distúrbios comportamentais (CHICON et al., 2019). A etiologia do autismo ainda é desconhecida, no entanto, relaciona-se a fatores genéticos, elevada idade dos pais, baixo peso do recém-nascido e exposição do feto ao ácido valproico (HOFZMANN et al., 2019).

De acordo com dados epidemiológicos, a prevalência do autismo no mundo é de 1 em cada 150 nascimentos, sendo que esses números vêm crescendo nas últimas décadas (ANJOS et al., 2017). Segundo Ferrari, cerca de 70\% das crianças autistas apresentam um grau de atraso mental e na linguagem, enquanto $30 \%$ apresentam uma inteligência acima da média, geralmente focada em algo específico, de seu interesse (ANJOS et al., 2017).

Pensando no desenvolvimento da criança, destaca-se a maturação neurológica. Nos casos do autismo, esse amadurecimento fica comprometido, interferindo na exploração externa da criança, justificando, dessa forma, algumas particularidades 
como o isolamento, ausência da busca pela aprendizagem, atitudes de oposição, dificuldades de iniciativa, concentração e de comunicação (ANJOS et al., 2017).

Os cuidadores são os primeiros a notarem as peculiaridades e especificidades que a criança autista apresenta e têm um importante papel no diagnóstico deste transtorno (BIFFI et al., 2019). Além das particularidades comportamentais, as crianças com autismo também podem apresentar uma diversidade de alterações motoras logo nos primeiros anos da infância, como alterações no equilíbrio, na marcha e na destreza manual (ANJOS et al., 2017). Devido aos déficits apresentados, as intervenções terapêuticas multiprofissionais fazem-se necessárias, objetivando-se 0 desenvolvimento da criança.

As intervenções terapêuticas têm como objetivo incentivar o autista em sua independência e devem ser planejadas de acordo com as potencialidades e necessidades da criança. Dentre elas, pode-se citar a psicomotricidade, sendo ela caracterizada como a interação do homem com o seu próprio corpo em movimento, levando em consideração o ambiente interno e externo. Por meio desta ciência, entende-se que o desenvolvimento da psicomotricidade se dá a partir de movimentos organizados e integrados, a partir das interações vividas pelo indivíduo (JESUS, 2019).

Outra intervenção que pode ser usada com este público é a realidade virtual. Essa ferramenta tecnológica faz com que o indivíduo se encontre em uma representação tridimensional, possibilitando que ele se movimente em vários ângulos. Esta interação pode ser utilizada com fins educacionais, lúdicos ou terapêuticos, visto que, na área da saúde, vem ganhando destaque no campo da reabilitação cognitiva e motora (SANTOS; OLIVEIRA, 2018).

Além das práticas citadas acima, destaca-se também a musicoterapia, que pode ser entendida como o uso da música para um determinado tratamento, objetivando principalmente a melhora da comunicação e interação social da criança autista. Esta intervenção proporciona ao indivíduo harmonia rítmica, melhora da capacidade de 
aprendizagem, além de ser um tratamento prazeroso (SAMPAIO; LOUREIRO; GOMES, 2015).

Diante dos aspectos apresentados acima, o objetivo do presente estudo foi discutir, por meio de uma revisão bibliográfica, a eficácia dos achados sobre a psicomotricidade, musicoterapia e realidade virtual como formas de tratamento da criança autista.

\section{DESENVOLVIMENTO}

Devido às várias alterações que podem afetar a criança autista, a forma de tratamento mais eficaz é a multiprofissional, haja vista que ela abrange um número maior de questões da síndrome, envolvendo o modelo biopsicossocial que a criança está inserida (GARCIA; NASCIMENTO; PEREIRA, 2017).

Evidencia-se a importância da estimulação precoce nessas crianças, antes dos três anos de idade, sendo necessário conhecer as fases e as características do desenvolvimento infantil. A estimulação precoce, por sua vez, consiste em auxiliar a função materna, pois nesse sentido o terapeuta terá contato direto com a criança, realizando suas intervenções (CRUZ; POTTKER, 2017).

De acordo com o Ministério da Saúde, a estimulação precoce é uma técnica que envolve os vários sistemas do organismo, sendo capaz de favorecer a plasticidade cerebral. Os estímulos são iniciados no período de 0 a 3 anos de idade, com o objetivo de evitar ou amenizar os déficits advindos do TEA, como as dificuldades motoras, cognitivas e comportamentais. Enfatiza-se, dessa forma, a importância da participação ativa dos membros da família, os quais têm um papel fundamental na estimulação das crianças, principalmente em relação ao comando verbal e ao estímulo tátil (CRUZ; POTTKER, 2017).

Dentre as várias terapias relevantes, algumas abordagens têm mais destaques pelo fato da criança se envolver afetivamente no processo, por exemplo: na equoterapia, a via psicomotora é ativada pelo animal, criando um laço entre indivíduo e cavalo; a 
musicoterapia, por sua vez, instiga a criança a se comunicar; e, por fim, a realidade virtual a atrai, por ser percebida como brincadeira terapêutica (JESUS, 2019; SAMPAIO; LOUREIRO; GOMES, 2015).

\section{PSICOMOTRICIDADE}

A criança autista tem uma grande dificuldade em compreender seu corpo como um todo, portanto, a noção de esquema corporal não é desenvolvida de forma pertinente. Azevedo e Gusmão (2016) afirmam também que o diagnóstico tardio gera problemas no padrão motor. Como é sabido que a demora do diagnóstico é algo comum, o tratamento fisioterapêutico, operando com a psicomotricidade, melhora o padrão motor e, consequentemente, a marcha e o equilíbrio, bem como a qualidade de vida da criança (OLIVEIRA et al., 2019).

A psicomotricidade é compreendida como a primeira manifestação de movimento e existe desde a vida intrauterina, pois é nesta fase que os primeiros movimentos corporais são conhecidos pelo feto e vão estruturar e influenciar os comportamentos desta nova vida. Neste sentido, a psicomotricidade pode ser entendida como um movimento organizado e integrado resultante da individualidade, linguagem e socialização do ser humano (JESUS, 2019).

Dessa forma, a psicomotricidade é uma forma de intervenção muito benéfica haja vista que favorece o desenvolvimento do ser humano nos seus aspectos corporais, motores, emocionais, intelectuais e sociais. Para tanto, ela não pode se limitar a robotização de habilidades; deve-se desenvolver o indivíduo integralmente, para que possa interagir e sentir-se parte do ambiente, sentindo-se livre para se manifestar através de seus movimentos (JESUS, 2019).

Um estudo feito por Anjos e colaboradores (2017) procurou compreender a percepção dos cuidadores sobre o tratamento fisioterapêutico em crianças autistas. Os autores concluíram que por mais que os cuidadores não soubessem explicar o desenvolvimento psicomotor obtido por suas crianças, a fisioterapia propiciou ganhos importantes aos pacientes, como melhora da função motora, equilíbrio e coordenação. 
E, segundo uma revisão integrativa feita por Oliveira e colaboradores (2019), a psicomotricidade contribui para que a criança autista consiga se expressar, aperfeiçoando, assim, os sistemas motor, cognitivo e sensorial, favorecendo principalmente a interação social.

Logo, é importante saber que o caminho para acessar estas crianças é o afetivo, desse modo, a necessidade de uma conexão afetiva sólida é indispensável para a construção de um diálogo tônico (KUMAMOTO, 1989). Uma das formas de acessar essa via é o uso de animais no tratamento fisioterapêutico como, por exemplo, a equoterapia.

É sabido que os autistas possuem forte empatia pelos equinos e formam laços com o animal (RIBEIRO et al., 2019). Neste sentido, a terapia com o cavalo atua não somente no desenvolvimento do esquema corporal, devido ao movimento tridimensional do animal que influencia diretamente na postura e no equilíbrio do praticante, mas também no lado cognitivo, emocional e social do indivíduo, uma vez que pode ser realizada em grupo e ao ar livre (CRUZ; POTTKER, 2017).

De acordo com uma revisão bibliográfica feita por Ribeiro e colaboradores (2019), a equoterapia proporciona vários benefícios em diversos aspectos, visto que além de melhorar o equilíbrio, a concentração e a postura, também estimula o lado social das crianças autistas.

A equoterapia precisa ser específica e deve se basear em atividades lúdicas, ainda que sejam utilizados determinados materiais, como bastões para a melhora da postura, e argolas e cones para equilíbrio e concentração (RIBEIRO et al., 2019). Assim, é indispensável que o fisioterapeuta tenha conhecimento da prática equoterápica como forma de tratamento psicomotor, com o propósito de realizar um trabalho eficaz para a criança autista. 


\section{REALIDADE VIRTUAL}

A Realidade Virtual (RV) é uma tecnologia recente, que surgiu diante dos avanços tecnológicos e da informática e que recentemente passou a ser levada em conta para fins terapêuticos. Os estudos trazem várias abordagens sobre o tema, na qual a RV pode ser definida como um ambiente ou uma experiência vivenciada, na qual o indivíduo se encontra em uma representação tridimensional, que é realizada por meio de um sistema de computador. A aplicação da realidade virtual vem ganhando destaque, uma vez que o indivíduo pode participar, interagir e ser capaz de realizar movimentos em diferentes ângulos (SANTOS; OLIVEIRA, 2018).

Outra vantagem do uso da realidade virtual inclui a capacidade que o indivíduo tem em manter maior controle sobre a intervenção, como maior engajamento, aceitação e menos distração durante a atividade imposta (SANTOS; OLIVEIRA, 2018; ANTÃO et al., 2020). Estudos abordam a associação da realidade virtual com a reabilitação tradicional, visto que ela proporciona aos indivíduos autistas uma interação cognitiva diferente do que eles estão acostumados (LUCA et al., 2019).

De acordo com a literatura, este é um método acessível no tratamento do autismo, já que esse indivíduo tem a capacidade de manter a sua atenção em algo que julga interessante. Nesse sentido, são propostas atividades individualizadas focadas nas suas potencialidades, visto que as propostas são escolhidas de acordo com os fatores que chamam a atenção da criança (LUCA et al., 2019).

Sobre o uso de recursos tecnológicos, muitas pesquisas têm mostrado a eficiência metodológica usando equipamentos de informática, como videogames, tablets, notebooks, smartphones e computadores. Segundo os estudos, a interação dos autistas com o mundo virtual busca melhorar o aprendizado dessa criança de maneira satisfatória (ALMEIDA, 2019).

Uma pesquisa feita por Luca e colaboradores (2019) buscou avaliar o efeito da terapia cognitivo-comportamental versus a combinação desta com a realidade virtual, para o tratamento de um menino autista. Os resultados da pesquisa mostraram que a RC: 58317

Disponível em: https://www.nucleodoconhecimento.com.br/saude/psicomotricidade-e- 
combinação gerou melhora nos processos de atenção e reorganização espacial na criança. Assim, os autores concluíram que a RV é uma ferramenta importante na abordagem da criança autista.

\section{MUSICOTERAPIA}

O uso da música para tratamento é milenar. Por se tratar de uma intervenção que utiliza os sons, a voz, o corpo e instrumentos, a musicoterapia tem papel preventivo, atua no desenvolvimento e restaura funções e potencialidades do indivíduo (ANJOS et al., 2017). Como é sabido que a criança autista tem alterações na fala, na interação social e na motricidade, a música, como forma de abordagem, vem sendo amplamente empregada para quebrar essas barreiras.

A plasticidade cerebral no TEA precisa ser trabalhada para que as habilidades, tanto motoras, como verbais e não-verbais sejam desenvolvidas. As áreas de processamento do som no autista não são afetadas e, assim, apresentá-lo a essa abordagem pode aumentar as conexões neurais em regiões de cognição, interação social e motricidade (ZIMER; RODRIGUES; FREITAS, 2018).

Estudos comprovam que crianças com TEA tem grande interesse por música e isso é um fator fundamental para o sucesso da terapia. Em razão de ser um estímulo afetuoso e simpático, a musicoterapia recompensa emocionalmente o autista (MOLNAR-SZAKACS; HEATON, 2012)

Um estudo de caso desenvolvido por Souza e colaboradores (2017) buscou avaliar a eficácia da linguagem musical no tratamento da criança autista. Para tanto, foram realizados encontros semanais com duração de 50 minutos, nos quais 11 músicas pré-estabelecidas eram cantadas, sendo que uma delas poderia ser escolhida pela criança. Ao final, concluíram que a música foi capaz de auxiliar na criação de vínculos e deve ser implementada na abordagem do tratamento.

Ao se envolver na terapia musical, o musicoterapeuta se adapta para incluir no tratamento o que o paciente necessita. Portanto, é necessário sintonizar 
musicalmente as qualidades fisiológicas, emocionais, criativas e lúdicas para atrair a criança. O participante, então, reproduz seu terapeuta e desenvolve habilidades que podem minimizar suas características típicas, como o excesso de movimento e a falta de atenção, por exemplo. Assim, a criança se reconhece e valida a interação musical como algo prazeroso e benéfico para ela (SAMPAIO; LOUREIRO; GOMES, 2015; EPSTEIN; ELEFANT; THOMPSON, 2019).

\section{CONSIDERAÇÕES FINAIS}

De acordo com os estudos revisados, a aplicação de terapias com diferentes abordagens tem resultados satisfatórios em crianças autistas. Os estudos evidenciam que a realidade virtual, a psicomotricidade e a musicoterapia são recursos relevantes para a prática clínica e com boa aceitação por parte do indivíduo com TEA.

Por meio da estimulação precoce, as intervenções abordadas contribuem para o desenvolvimento cognitivo, sensorial, motor, social e linguístico das crianças com TEA. A utilização destes recursos terapêuticos é capaz de motivar a criança a contribuir para que o tratamento seja realmente significativo.

Dada a importância do tema, torna-se necessário o desenvolvimento de novos estudos sobre a associação das intervenções abordadas, uma vez que o número de crianças autistas vem crescendo nos últimos anos, e se faz necessário competências e habilidades para garantir um atendimento multiprofissional de qualidade para esta criança.

\section{REFERÊNCIAS}

ALMEIDA, Glória Maria Ribeiro de. As contribuições dos recursos tecnológicos no processo de ensino aprendizagem do autista. Revista Científica Multidisciplinar Núcleo do Conhecimento, v. 07, p. 16-34, 2019. Disponível em: https://www.nucleodoconhecimento.com.br/educacao/contribuicoes-dos-recursos > Acesso em: 20 mar. 2020 
ANJOS, Alexandre Gonzaga et al. Musicoterapia Como Estratégia De Intervenção Psicológica Com Crianças: Uma Revisão Da Literatura. Revista Interinstitucional de Psicologia, v. 10, n. 2, p. 228-238, 2017. Disponível em: http://pepsic.bvsalud.org/pdf/gerais/v10n2/08.pdf > Acesso em: 20 abr. 2020.

ANJOS, Clarissa Cotrim et al. Percepção dos Cuidadores de Crianças com Transtorno do Espectro Autista sobre a Atuação da Fisioterapia. Revista Portal: Saúde e Sociedade, v. 2, n.3, p. 517-532, 2017. Disponível em: http://www.seer.ufal.br/index.php/nuspfamed/article/view/3246 > Acesso em: 31 mar. 2020.

ANJOS, Clarissa Cotrim et al. Perfil Psicomotor de Crianças com Transtorno do Espectro Autista em Maceió/AL. Revista Portal: Saúde e Sociedade, v. 2, n. 2, p. 395410 , 2017.

Disponível

em: http://www.seer.ufal.br/index.php/nuspfamed/article/view/3161 > Acesso em: 31 mar. 2020.

ANTÃO, Jennifer Yohanna Ferreira de Lima et al. Use of Augmented Reality With a Motion-Controlled Game Utilizing Alphabet Letters and Numbers to Improve Performance and Reaction Time Skills for People with Autism Spectrum Disorder. Cyberpsychology, Behavior, and Social Networking, v. 23, n. 1, p. 16-22, 2020. Disponível em: https://www.ncbi.nlm.nih.gov/pubmed/31976770 > Acesso em: 30 mar. 2020.

AZEVEDO, Anderson; GUSMÃO, Mayra. A Importância Da Fisioterapia Motora No Acompanhamento De Crianças Autistas. Revista Eletrônica Atualiza Saúde, v. 3, n. 3, p. 76-83, 2016. Disponível em: http://atualizarevista.com.br/article/a-importancia-dafisioterapia-motora-no-acompanhamento-de-criancas-autistas-v-3-n3/ > Acesso em: 10 abr. 2020

BIFFI, Débora et al. Percepções sobre o autismo sob a ótica das mães. Revista enfermagem atual, v. $87, \quad$ n. 25, p. 01-06, 2019. Disponível em: 
https://revistaenfermagematual.com.br/index.php/revista/article/view/222 > Acesso em: 31 mar. 2020.

CHICON, José Francisco et al. Brincando e aprendendo: aspectos relacionais da criança com autismo. Revista Brasileira de Ciência do Esporte, v. 41, n. 2, p. 169-175, 2019. Disponível em: https://www.scielo.br/scielo.php?script=sci_arttext\&pid=S010132892019000200169 > . Acesso em: 31 mar. 2020.

CRUZ, Brenda Darienzo Quinteiro; POTTKER, Caroline Andrea. As contribuições da equoterapia para o desenvolvimento psicomotor da criança com Transtorno de Espectro Autista. Revista UNINGÁ. Maringá, v. 32, n. 1, p. 147-158, 2017. Disponível em: http://revista.uninga.br/index.php/uningareviews/article/view/143 > Acesso em: 30 mar. 2020.

EPSTEIN, Shulamit; ELEFANT, Cochavit; THOMPSON, Grace. Music Therapists' Perceptions of the Therapeutic Potentials Using Music When Working With Verbal Children on the Autism Spectrum: A Qualitative Analysis. Journal of Music Therapy, v. 20, n. 20, p. 01-25, 2019. Disponível em: https://academic.oup.com/jmt/articleabstract/57/1/66/5670486? redirectedFrom=fulltext > Acesso em: 20 abr. 2020.

GARCIA, Sônia Cardoso Moreira; NASCIMENTO, Mayara Andrine; PEREIRA, Marília. Autismo Infantil: Acolhimento E Tratamento Pelo Sistema Único De Saúde. Revista Valore, v. 2, n. 1, p. 155-167, 2017. Disponível em: https://revistavalore.emnuvens.com.br/valore/article/view/35 > Acesso em: 29 mar. 2020.

HOFZMANN, Rafaela da Rosa et al. Experiência dos familiares no convívio de crianças com transtorno do espectro autista (TEA). Revista Enfermagem em foco. v. $10, \quad$ n. $\quad 2, \quad$ p. $\quad 64-69, \quad 2019.2$ Disponível em: http://revista.cofen.gov.br/index.php/enfermagem/article/view/1671 > Acesso em: 31 mar. 2020. 
JESUS, Sara Gonçalves. Educação Psicomotora No Desenvolvimento De Criança Com Autismo. Revista Digital Diamantina Presença, v. 2, n. 1, p. 78-87, 2019. Disponível em: https://www.revistas.uneb.br/index.php/diamantina/article/view/7514 > Acesso em: 30 mar. 2020.

KUMAMOTO, Laura Helena Montenegro Carneiro da Cunha. Autismo - Uma Abordagem Psicomotora. Psicologia: Teoria e Pesquisa, v. 5, n. 2, p. 231-238, 1989. Disponível em:https://webcache.googleusercontent.com/search?q=cache:EYR14ptNdZoJ:https:/ /periodicos.unb.br/index.php/revistaptp/article/download/17071/15557/+\&cd=3\&hl=ptBR\&ct=clnk\&gl=br > Acesso em: 10 abr. 2020.

LUCA, Rosaria et al. Innovative use of virtual reality in autism spectrum disorder: A case-study. Applied Neuropsychology: Child. p.1-11, 2019. Disponível em: https://www.tandfonline.com/doi/ref/10.1080/21622965.2019.1610964?scroll=top > Acesso em 20 abr. de 2020.

MOLNAR-SZAKACS, Istvan; HEATON, Pamela. Music A Unique Window Into The World Of Autism. Annals Of The New York Academy Of Sciences, p. 318-324, 2012. Disponível em: https://www.ncbi.nlm.nih.gov/pubmed/22524374\# > Acesso em: 20 abr. 2020.

OLIVEIRA, Érica Monteiro et al. O impacto da Psicomotricidade no tratamento de crianças com transtorno do Espectro Autista: revisão integrativa. Revista Eletrônica Acervo Saúde, v. 34, 2019. Disponível em: https://acervomais.com.br/index.php/saude/article/view/1369 > Acesso em: 30 mar. 2020.

RIBEIRO, Fernanda de Oliveira et al. Os Efeitos Da Equoterapia Em Crianças Com Autismo. Fisioterapia Brasil, v. 20, n. 5, p. 684-691, 2019. Disponível em: https://portalatlanticaeditora.com.br/index.php/fisioterapiabrasil/article/view/2703 > Acesso em: 30 mar. 2020. 
SAMPAIO, Renato Tocantins; LOUREIRO, Cybelle Maria Veiga; GOMES, Cristiano Mauro Assis. A Musicoterapia e o Transtorno do Espectro Do Autismo: Uma Abordagem Informada Pelas Neurociências Para A Prática Clínica. Per musi [online], n. 32, p. 137-170, 2015. Disponível em: https://www.scielo.br/scielo.php?pid=S151775992015000200137\&script=sci_abstract\&tlng=pt > Acesso em: 20 abr. 2010.

SANTOS, Lucileide Vieira; OLIVEIRA, Jorge Gaspar. Realidade virtual com fins terapêuticos. Revista de Psicologia da Criança e do Adolescente, v. 9, n. 1, p. 105127 , 2018.

Disponível em http://revistas.lis.ulusiada.pt/index.php/rpca/article/view/2675/2891 Acesso > em: 30 mar. 2020.

SOUZA, Marina Batista et al. Da Vibração Ao Encontro Com O Outro: Psicanálise, Música E Autismo. Estilos da Clínica, v. 22, n. 2, p. 299-317, 2017. Disponível em: http://pepsic.bvsalud.org/scielo.php?script=sci_arttext\&pid=S141571282017000200006 > Acesso em: 29 mar. 2020.

ZIMER, Paulyane Nascimento; RODRIGUES, Jéssika Castro; FREITAS, Áureo Déo. Educação Musical E Transtorno Do Espectro Autista: Análise Da Produção Em Revistas Brasileiras De Artes/Música Qualis A1 E Seus Anais De Eventos Regionais E Nacionais (2006-2016). Revista da Associação Brasileira Musical, v. 26, n. 40, p. 149-166, 2018.

Disponível em: http://www.abemeducacaomusical.com.br/revistas/revistaabem/index.php/revistaabe m/article/view/760 > Acesso em: 20 Abr. 2020.

Enviado: Agosto, 2020.

Aprovado: Agosto, 2020. 